\title{
Improvement of HIV-related pulmonary hypertension after the introduction of an antiretroviral therapy
}

\section{To the Editors:}

The potential impact of combination antiretroviral therapy (CART) on HIV-related pulmonary arterial hypertension (PAH) remains controversial [1-4]. We herein report the case of a dramatic improvement in PAH at the time of the inception of CART in a 19-yr-old female with HIV-1 infection due to motherto-child transmission. HIV-related PAH was diagnosed in January 2006, when she was stable in stage A2 of the US Centers for Disease Control and Prevention classification without any antiretroviral therapy (table 1). Specific PAH therapy with bosentan was started in January 2006, in combination with oral anticoagulant and diuretic therapy. CART was indicated at that time, but not prescribed owing to patient refusal. Her clinical condition slowly deteriorated (onset of major bilateral lower limb oedema and functional New York Heart Association (NYHA) class IV) until June 2006, leading to hospitalisation: right heart catheterisation revealed further haemodynamic deterioration (table 1). Continuous intravenous epoprostenol therapy was added, and a dose of $15 \mathrm{ng} \cdot \mathrm{kg}^{-1} \cdot \mathrm{min}^{-1}$ was reached in September 2006. At that time, it was decided to commence antiretroviral therapy, including lopinavir, ritonavir, emtricitabine and tenofovir disoproxil. Simultaneously, the epoprostenol dose was increased to $25 \mathrm{ng} \cdot \mathrm{kg}^{-1} \cdot \mathrm{min}^{-1}$, reached in March 2007. A sustained improvement in her clinical condition was observed from the end of November 2006. Since January 2007, the viral load has been undetectable and the CD4 count has gradually risen to $>500$ cells $\cdot \mathrm{mm}^{-3}$. Treatments for PAH and HIV infection have remained unchanged and a right heart catheterisation, performed in September 2007, demonstrated a dramatic improvement (table 1). As the patient was in functional NYHA class I, it was decided to cautiously decrease the i.v. epoprostenol doses until its interruption, achieved in February 2008. Bosentan and CART were maintained unchanged. A right heart catheterisation, performed a few weeks after epoprostenol interruption, confirmed the stable results (table 1).

This case report is remarkable, because first, in contradiction with previous reports on the effectiveness of these drugs in such a setting, a flare-up of PAH occurred despite the step-up in specific therapy with the combination of oral bosentan and i.v. epoprostenol. As an example, in the open-label study by SitBON et al. [2], which evaluated the administration of bosentan in HIV-related PAH, an improvement in the 6-min walk distance was observed in all patients at week 16 . Secondly, a dramatic clinical and haemodynamic improvement paralleled the introduction of CART and, furthermore, the withdrawal of epoprosterol was achieved. Data on the impact of CART on PAH are scarce and conflicting, with reports of either improvement $[5,6]$ or worsening $[7,8]$. One open-label 6-month study compared, in 36 previously untreated HIVinfected patients with $\mathrm{PAH}$, the effect of the introduction of CART alone and the combination of CART and bosentan [9]: at week 24, a significant decrease in mean pulmonary artery pressure from baseline was observed in the subgroup receiving the combination of CART and bosentan; this was not observed in the subgroup receiving CART alone. As case reports point to variable therapeutic responses of $\mathrm{PAH}$ to antiretroviral therapies, larger studies including HIV-related PAH patients with high CD4 counts are needed [10].

\section{A. Barnier, I. Frachon, J. Dewilde, C. Gut-Gobert, Y. Jobic and C. Leroyer \\ Dept of Internal Medicine and Pneumology, Groupe HTAP de Bretagne Occidentale, GETBO, EA 38 78, Hôpital Universitaire de la Cavale Blanche, Brest, France.}

TABLE 1 Evolution of main clinical, biological and haemodynamic parameters

\begin{tabular}{|c|c|c|c|c|c|c|c|c|c|}
\hline 6MWD m & 324 & 328 & 257 & 278 & 350 & 424 & 534 & 563 & 623 \\
\hline CD4 cells $\cdot \mathrm{mm}^{-3}$ & 454 & 471 & 316 & 404 & 657 & 268 & 480 & 510 & 850 \\
\hline Viral load copies $\log _{10} \mathrm{~mL}^{-1}$ & 4.96 & 4.63 & 4.97 & 2.21 & 2.41 & 1.32 & 1.32 & 1.32 & 1.32 \\
\hline Pra $\mathrm{mmHg}$ & 12 & 16 & & & & & & 4 & 4 \\
\hline PVR Wood units & 22.2 & 25 & & & & & & 5 & 5.4 \\
\hline Cardiac index $\mathrm{L} \cdot \mathrm{min}^{-1} \cdot \mathrm{m}^{-2}$ & 1.8 & 1.8 & & & & & & 3.1 & 2.9 \\
\hline
\end{tabular}

\#: introduction of combination antiretroviral therapy was performed closely after the September 2006 check-up. NYHA: New York Heart Association; 6MWD: 6-min walk distance; BNP: brain natriuretic peptide; $\bar{P}_{\text {pa: }}$ mean pulmonary artery pressure; Pra: right atrial pressure; PVR: pulmonary vascular resistance. 
Correspondence: I. Frachon, Dept of Internal Medicine and Chest Diseases, Hôpital de la Cavale Blanche, F-29609 Brest Cedex, France. E-mail: irene.frachon@chu-brest.fr

Statement of Interest: None declared.

\section{ACKNOWLEDGEMENTS}

The authors wish to thank P. Perfezou (Centre Hospitalier de Cornouailles, Quimper, France) and O. Sitbon (Hôpital Antoine Béclère, Clamart, France) for kindly providing useful medical expertise.

\section{REFERENCES}

1 Sitbon O, Lascoux-Combe C, Delfraissy JF, et al. Prevalence of HIV-related pulmonary arterial hypertension in the current antiretroviral therapy era. Am J Respir Crit Care Med 2008; 177: 108-113.

2 Sitbon O, Gressin V, Speich R, et al. Bosentan for the treatment of human immunodeficiency virus-associated pulmonary arterial hypertension. Am J Respir Crit Care Med 2004; 170: 1212-1217.

3 Zuber JP, Calmy A, Evison JM, et al. Pulmonary arterial hypertension related to HIV infection: improved hemodynamics and survival associated with antiretroviral therapy. Clin Infect Dis 2004; 38: 1178-1185.
4 Sitbon O. HIV-related pulmonary hypertension: clinical presentation and management. AIDS 2008; 22: Suppl. 3, S55-S62.

5 Feiterna-Sperling C, Huseman D, Timme J, et al. Resolution of human immunodeficiency virus type 1 infection-related severe pulmonary hypertension in a very low-birth-weight infant. Pediatr Infect Dis J 2008; 27: 564-567.

6 Speich R, Jenni R, Opravil M, et al. Regression of HIV-associated pulmonary arterial hypertension and long-term survival during antiretroviral therapy. Swiss Med Wkly 2001; 131: 663-665.

7 Pellicelli AM, Barbaro G, Palmieri F, et al. Primary pulmonary hypertension in HIV patients: a systematic review. Angiology 2001; 52: 31-41.

8 Pellicelli AM, D'Ambrosio C, Vizza CD, et al. HIV-related pulmonary hypertension. From pathogenesis to clinical aspects. Acta Cardiol 2004; 59: 323-330.

9 Barbaro G, Lucchini A, Pellicelli AM, et al. Highly active antiretroviral therapy compared with HAART and bosentan in combination in patients with HIV-associated pulmonary hypertension. Heart 2006; 92: 1164-1166.

10 Torre D, Pugliese A. Impact of antiretroviral therapy among HIV-1-infected patients with pulmonary hypertension. Clin Infect Dis 2004; 39: 1549-1550.

\section{Intravenous $\alpha_{1}$-antitrypsin in a child with deficiency and severe lung disease}

Hereditary $\alpha_{1}$-antitrypsin deficiency presents with symptomatic obstructive and suppurative lung disease usually in the fourth decade in individuals with a history of smoking [1, 2].

A mature neonate had prolonged icterus due to $\alpha_{1}$-antitrypsin deficiency (PiZZ-type). At 4 weeks of age she developed transient middle lobe atelectasis and persisting hyperinflation on chest radiographs. The patient was hospitalised for virus induced wheezing, bronchopneumonic episodes and atelectasis of the middle lobe many times throughout childhood. Chest computed tomography imaging showed basal emphysema and bronchiectasis in the middle lobe and lingula. Heavy passive smoke exposure was known to have occurred from infancy onward, with active smoking possibly occurring in adolescence for brief periods.

She attended our centre regularly from the age of $12.5 \mathrm{yrs}$. Cystic fibrosis, ciliary dyskinesia, structural bronchopulmonary abnormalities, gastroeso-ophageal reflux-induced lung disease, immune deficiency states, allergies and allergic asthma were excluded. Treatment intensity remained high over the years. At age $14 \mathrm{yrs}$, weekly intravenous augmentation with $60 \mathrm{mg} \cdot \mathrm{kg}^{-1} \cdot$ body weight ${ }^{-1}$ of $\alpha_{1}$-antitrypsin (Prolastin; Bayer, Wuppertal, Germany) was started. Continuous treatment with bronchodilators, inhaled steroids and cefuroxime was left unchanged. Her overall condition improved markedly, and the number of exacerbations, defined according to ANTHONISEN et al. [3], was reduced (fig. 1a) and lung function studies showed decreased airways obstruction and decreased hyperinflation (fig. 1b). Arrest of basal emphysematous changes and bronchiectasis was seen on computed tomography after 4 yrs of treatment. Before $\alpha_{1}$-antitrypsin therapy her bodyweight had been below or at the 3rd percentile for many years and we had encouraged her to take supplemental calories (fig. 1c). Her weight increased rapidly, in association with her improved pulmonary condition, although unintended weight gain subsequently occurred, with dietary intervention being successful only recently.

This is an example of the characteristic course of $\alpha_{1}$-antitrypsin lung disease, which is commonly observed in adults, occurring in a teenager. Among the reasons for such a precocious manifestation of this inherited disease may be as yet unknown endogenous factors and clearly exogenous factors. These included long-standing passive and later possibly active tobacco smoke exposure, frequent and severe lower respiratory tract infections, significant psychosocial family problems and, potentially, malnutrition.

Based on an urgent need for stabilisation of the lung disease and the experience in the adult population, i.v. $\alpha_{1}$-antitrypsinaugmentation therapy was started. According to current 